\section{Cost-effectiveness Analysis of a Strawberry Breeding Program Incorporating DNA-informed Technology}

\author{
Seth D. Wannemuehler ${ }^{1}$, Chengyan Yue ${ }^{1}$, \\ Wendy K. Hoashi-Erhardt ${ }^{2}$, R. Karina Gallardo ${ }^{3}$, \\ and Vicki McCracken ${ }^{4}$
}

\begin{abstract}
ADDITIONAL INDEX WORDs. calculator, Fragaria $\times$ ananassa, rosaceous fruit, spreadsheet, strawberry

SumMARY. DNA-informed breeding techniques allow breeders to examine individual plants before costly field trials. Previous studies with tree fruits such as apple (Malus $\times$ domestica) and peach (Prunus persica) have identified cost-effective implementation of DNA-informed techniques. However, it is unclear whether breeding programs for herbaceous perennials with 1 - to 2 -year juvenile phases benefit economically from these techniques. In this study, a cost-benefit analysis examining marker-assisted selection (MAS) in a Pacific northwest U.S. strawberry (Fragaria $\times$ ananassa) breeding program was conducted to elucidate the effectiveness of DNA-informed breeding in perennial crops and explore the capabilities of a decision support tool. Procedures and associated costs were identified to create simulations of the breeding program. Simulations compared a conventional breeding program to a breeding program using MAS with low (12.5\%), medium $(\mathbf{2 5} \%)$, and high $(\mathbf{5 0} \%)$ removal rates, and examined different scenarios where MAS had diminishing power to remove individuals as selections reenter the breeding cycle as parent material. We found that MAS application under current costs was not cost-effective in the modeled strawberry program when applied at the greenhouse stage, but cost-effectiveness was observed when MAS was applied at the end of the seedling trials before clonal trials with a removal rate of $12.5 \%$.
\end{abstract}

Received for publication 1 Oct. 2019. Accepted for publication 27 Feb. 2020.

Published online 9 April 2020.

${ }^{1}$ Department of Horticultural Science, University of Minnesota, 1970 Folwell Avenue, St. Paul, MN 55108

${ }^{2}$ Department of Horticulture and Landscape Architecture, Puyallup Research and Extension Center, Washington State University, 7612 Pioneer Way East, Puyallup, WA 98371

${ }^{3}$ School of Economic Sciences, Tree Fruit Research and Extension Center, Washington State University, 1100 N. Western Avenue, Wenatchee, WA 98801

${ }^{4}$ School of Economic Sciences, Washington State University, P.O. Box 646210, Hulbert Hall 30A, Pullman, WA 99164

Funding for RosBREED: Combining disease resistance with horticultural quality in new rosaceous cultivars is provided by the Specialty Crop Research Initiative Competitive Grant 2014-51181-22378 of the U.S. Department of Agriculture's National Institute of Food and Agriculture.

S.D.W. is a Graduate Research Assistant.

C.Y. is a Professor and Bachman Endowed Chair in Horticultural Marketing.

R.K.G. is an Associate Professor, Extension Specialist.

V.M. is a Professor.

C.Y. is the corresponding author. E-mail: yuechy@ umn.edu.

This is an open access article distributed under the CC BY-NC-ND license (https://creativecommons.org/ licenses/by-nc-nd/4.0/).

https://doi.org/10.21273/HORTTECH04519-19 genome of woodland strawberry [Fragaria vesca $(2 n=2 x=14)$ ] was sequenced, which is homologous to subgenomes of the allooctoploid genome of cultivated strawberry $(2 n=$ $8 x=56$ ) (Shulaev et al., 2011; Whitaker, 2011). This homology enables the development of DNA markers or specific pieces of DNA located near genes controlling traits of interest. Associations between DNA markers and variation of traits in a population for a trait of interest are analyzed using statistical methods (Miles and Wayne, 2008), and an identified genomic location associated with variation for the trait is called a quantitative trait locus (QTL) (Frey et al., 2004). These advancements in genetic understanding have led to the development of a new method of plant breeding. Breeders can use DNA marker tests to identify individual plants (hereafter referred to as individuals) possessing the desired QTL, enabling faster breeding decisions earlier in a program.

One method of DNA-informed breeding involves examination of DNA of seedlings, and it is referred to as marker-assisted seedling selection (MASS). Another method involves examination of parent material before crosses occur and is commonly referred to as marker-assisted parental selection (MAPS). These are two types of marker-assisted selection (MAS) useful for their potential to improve rate of selection and quality in a breeding program (Collard and Mackill, 2008). Studies have explored the use of MAS in field crops, such as maize [Zea mays (Johnson, 2003; Knapp, 1998; Stromberg et al., 1994)], potato [Solanum tuberosum (Slater et al., 2013)], soybean [Glycine max (Hoeck et al., 2003)], and wheat [Triticum aestivum (Kuchel et al., 2005)], and a subset have examined economic impacts associated with this technology. Alpuerto et al. (2009) showed that MAS incorporation in rice (Oryza satvia) breeding resulted in additional costs compared with conventional breeding but reduced the time to cultivar release. Quicker cultivar release resulted in increased economic gains by balancing higher MAS-related costs with reduced length of costs occurring, ultimately resulting in cost-effective MAS. Consistent with these findings, Dreher et al. (2003) and Morris et al. (2003) compared MAS 
and conventional breeding methods in agronomic crops and showed that incorporation of MAS in breeding schemes reduces time or cost requirements.

Without knowledge of how MAS could impact a breeding program economically, breeders may be less likely to adopt this technology; and to our knowledge, limited studies have investigated economic impacts of MAS in horticultural breeding programs (Ru et al., 2015). One study concluded that the probability of more cost-effective MAS is impacted by conditions such as the inheritance of the trait, the timing of trait expression, MAS application timing, conventional screening costs, robust marker-trait associations, and the probability of selecting superior individuals using MAS (Luby and Shaw, 2001). A second study by Edge-Garza et al. (2015) used these conditions to generate the MASS Efficiency Calculator v. 1.0 using apple (Malus $\times$ domestica), grape (Vitis vinifera), and strawberry as model crops. They concluded that the stage in the breeding program in which MASS was employed was less important in predicting costeffectiveness than both removal rates' reduction due to MASS and conventional seedling removals. They further determined that application of MASS as early as possible was not necessary if MASS occurred before additional labor costs are incurred from seedling handling [e.g., planting in fields with annual maintenance (Edge-Garza et al., 2015)].

In this study, we incorporate the dynamic nature of perennial plant breeding into a decision support tool to provide an overview of a dayneutral strawberry breeding program. Breeding programs differ in procedures, costs, or both, which results in every program having unique cost structures. This makes the creation of adaptable spreadsheet-based calculators challenging and often requires new development of specialized budgets, which may prevent its use by breeders (Ru et al., 2015). Overcoming this challenge requires detailed inputs from breeders, breeding program records, and a flexible decision support tool (Wannemuehler et al., 2019). The decision support tool created by Wannemuehler et al. (2019) should be capable of accommodating a breeding program's unique objectives, thus enabling breeders to make breeding program cost estimations for different scenarios.

\section{Materials and methods}

A model of the Washington State University day-neutral (DN) strawberry breeding program was developed to examine procedural costs and costs associated with MAS incorporation. The model used itemized costs incurred by the strawberry breeding programs during the 2017 field season. Details regarding procedures and timing of operations were provided by breeding program coordinators, who developed a timeline from parental crosses to grower trials before commercialization.

The strawberry breeding program included six stages: crossing, greenhouse growth, seedling trials, clonal replication trials, clonal replication with repetition trials, and grower trials (Fig. 1). Costs were collected as labor costs and consumable costs for each stage. Crossing stage procedures include germplasm maintenance, parental cross planning, crossing, seed collection, and stratification.
Greenhouse growth procedures include germination until just before field planting. Seedling trials procedures consist of costs for site preparation, maintenance, evaluations, and removal. Removal may be due to low vigor, disease susceptibility, poor growth habit, or other characteristics not desired in the seedlings. During seedling trials, based on breeder inputs, selections are normally distributed throughout the 3 years of seedling evaluations, with selections then progressing to clonal replication trials. Clonal replication costs include propagation, site preparation, maintenance, evaluation, and removal over a 3-year period. Selections from clonal replication trials are chosen based on the probability that as the number of seedlings currently in the trial and the quantity of seedlings entering the trial increase, likelihood of selection increases. Selections from clonal trials then move to clonal trials with field repetition where costs per plant are like clonal trials without field repetition. After 3 years of evaluations, some selections in clonal replicated

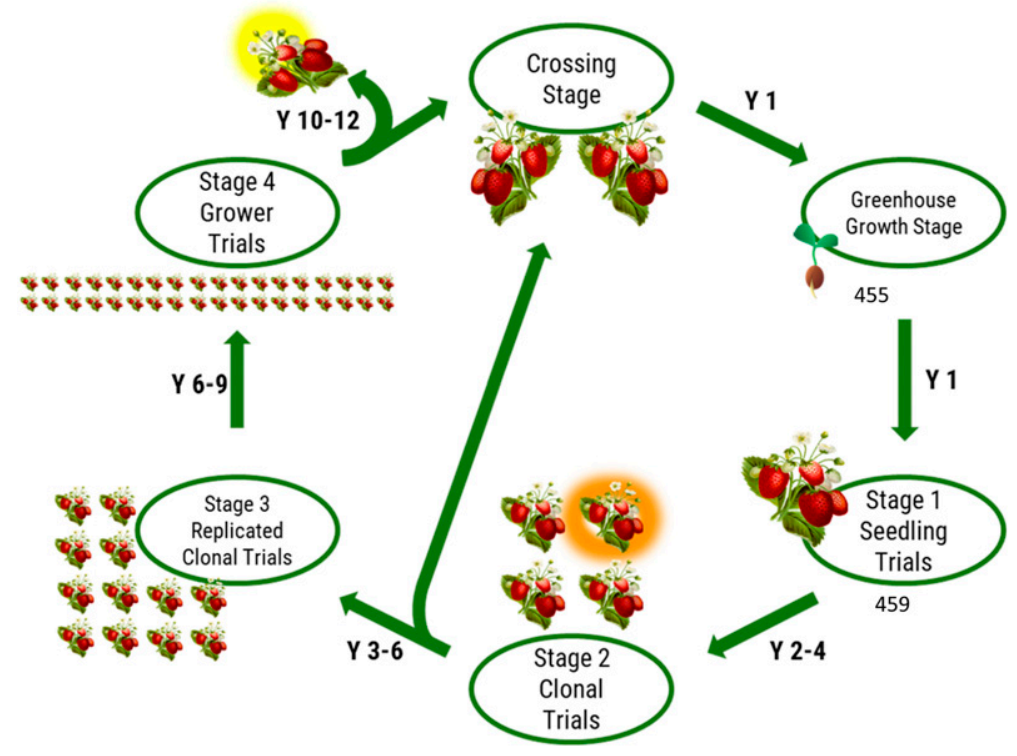

Fig. 1. Strawberry breeding program diagram following a single cohort of crosses through to selection release as a cultivar between years 10 and 12 and reentry into the program as a parent. Crosses are made in the spring of the first season with seed collection at the end of the same season. Seeds are germinated and then planted at the start of the second season. Seedlings remain in seedling trials for years 2 to 4 . During this time selections are made that advance to clonal trials. Selections remain here for years 3 to 6 during which time advanced selections occur. At the end of clonal trials, advanced selections may be incorporated as parents and/or continue as selections. Advanced selections move to replicated clonal trials and remain here from years 6 to 9. During this time pre-commercialization selections are chosen from grower trials and commercialization where they remain for years 10 to 12 in the program. 
Table 1. Conventional breeding methods' total costs for 10 years of crosses with no marker-assisted selection application for an observed strawberry breeding program.

\begin{tabular}{lcc}
\hline Stage & Yr & Total cost $(\$)$ \\
\hline Crossing & 1 & 130,480 \\
Greenhouse growth & 1 & 93,800 \\
Seedling trials & 2 & 51,280 \\
& 3 & 40,400 \\
Clonal trials & 4 & 41,280 \\
& 4 & 40,934 \\
& 5 & 27,462 \\
Clonal replicated & 6 & 27,524 \\
$\quad$ trials & 5 & 63,680 \\
& 6 & 55,200 \\
Grower trials & 7 & 55,200 \\
Total & 7 & 46,880 \\
\hline
\end{tabular}

trials move to grower trials where site preparation and plot maintenance costs are absorbed by growers.

To create simulations based on this model, six assumptions were made to allow modeling of the program over several years. 1) Environmental effects during the year of data collection are assumed average and consistent across years. 2) Costs during the year of data collection are representative of typical yearly expenditures. 3) Fixed costs (i.e., land rental, irrigation costs, machinery costs) are constant across years. 4) Markers exist for the purpose of selecting individuals in a breeding program. Two assumptions were made addressing the variable nature of DNA test development and genetics of targeted characteristics for the modeled program. 5) The cost of marker development is not included but the potential for substantial marker development costs is recognized. 6) Markers in this program scenario test for genes associated with dominant traits of simple genetic inheritance to allow modeling of reduction in marker effectiveness.

To estimate total costs associated with cultivar development in the program, costs for 10 years of hybrid crosses and subsequent evaluation stages were estimated. An average year in the strawberry program can result in $\approx 3500$ seedlings planted in seedling trials, and yearly crosses result in continuous cycling of costs because previous years' crosses are screened while new crosses are planted (Table 1). As time progresses, the overlapping trials create a dynamic cost structure for the program. The overlap is especially evident between seedling trials and clonal trials where selections occur over a period of 3 years per cross with the first and second year of selections overlapping with previous crosses. Using breeder estimation for the number of typical seedling trial selections per year, combined with the assumption that the distribution of selections follows a normal distribution, a system was developed for randomization in the number of selections per year by weighting selections based on the number of individuals in a particular trial.

Once a selection advances to clonal trials, selection for further trials occurs randomly among all selections present in a given year. Additionally, as a selection pool increases, the likelihood of selection advancement also increases. The model attempts to capture these two concepts by randomizing selection advancement using the probability of selection weighted by the number of advanced selections present during that year in clonal trials. This method creates a greater probability of selection advancement where more advanced selections are present. Clonal trials costs were simulated 50 times per model, and the average cost was calculated for each procedure. As selections continue, entries into clonal replicated trials are randomized based on clonal trial selection randomization weighted by the number of individuals present in a given year. Clonal replicated trials are followed by evaluation and progression to grower trials.

Marker-assisted selection is integrated at the end of greenhouse growth, based on previous literature indicating this as cost-efficient timing (Edge-Garza et al., 2015; Luby and Shaw, 2001). For greater modeling accuracy, the effectiveness of MAS to remove seedlings as the program timeline progresses was decreased under the assumption that as seedlings cycle back to become parents repetitively, their traits become fixed in the program. In this model, a single, simply inherited dominant trait was introduced in the first year of crossing with a marker test capable of detecting trait presence or absence. Based on these assumptions, $50 \%$ of seedlings would be removed from the marker test until seedling selections become parents, at which point seedling removal would drop to $25 \%$. Finally, no removal would be made based on the single marker test due to its associated trait becoming fixed in the population. From this assumption and communications with the breeders, simulations examining discounts for MAS pricing were estimated at three levels: $10 \%, 25 \%$, and $50 \%$ cost reductions (Table 2 ). Then a model was constructed holding seedling removal constant at a $50 \%$ removal rate with all other procedures remaining the same. Impacts of discount levels estimated from breeder expectations were then examined for MAS costs at $10 \%, 25 \%$, and $50 \%$ cost reductions (Table 3 ). A third MAS simulation was conducted where MAS implementation occurred at the end of seedling trials before clonal trials entry. Three removal rates based on the assumption of multiple DNA tests being applied were used $(12.5 \%$, $25 \%$, and $50 \%$ ) while costs and procedures were held constant from crossing to the end of seedling trials (Table 4). Removal rates were held constant throughout the program.

SENSITIVITY ANALYSES. Data from the breeding program shows that labor costs constitute a majority of program operational costs at $\approx 83 \%$ of total program costs. With scientific innovations occurring frequently, additional opportunities to improve program efficiency become likely. MAS is one innovation that has garnered incorporation in recent years. To examine the wider applications of this tool, we conducted sensitivity analyses examining possible decreases in labor costs via decreases in labor time needed based on breeder estimations of future labor practices.

According to gathered data, seedling maintenance costs comprise most program field trial costs. To elucidate cost savings associated with technologies other than MAS, simulations were conducted with discounts for seedling maintenance total costs. The baseline model assumes that MAS was selecting for a simply inherited trait that decreases in effectiveness with subsequent generations. Maintenance costs were discounted by $5 \%, 10 \%$, and $15 \%$ for seedling trials through grower trials, assuming everything else remains the same (Table 5). A second sensitivity 
Table 2. Marker-assisted selection (MAS) simulation 1 showing breeding program costs over 10 years of crosses in a strawberry breeding program with removal occurring after MAS application at the end of the greenhouse growth stage. ${ }^{\mathrm{z}}$ Discounts in total MAS technology costs are examined at three levels: $10 \%, 25 \%$, and $50 \%$ with all other costs held constant.

\begin{tabular}{|c|c|c|c|c|c|c|}
\hline Stage & Yr & $\begin{array}{l}\text { Cost of } \\
\text { MAS }(\$)\end{array}$ & $\begin{array}{c}\text { Greenhouse growth } \\
\text { MAS discount } 10 \%(\$)\end{array}$ & $\begin{array}{l}\text { Greenhouse growth } \\
\text { MAS discount } 25 \%(\$)\end{array}$ & $\begin{array}{l}\text { Greenhouse growth } \\
\text { MAS discount 50\% (\$) }\end{array}$ & $\begin{array}{c}\text { Break-even } \\
\text { point: } 95.41 \% \\
(\$)\end{array}$ \\
\hline Crossing & 1 & 130,480 & 130,480 & 130,480 & 130,480 & 130,480 \\
\hline Seedling trials & 2 & 30,768 & 30,768 & 30,768 & 30,768 & 30,768 \\
\hline \multirow[t]{3}{*}{ Clonal trials } & 4 & 40,934 & 40,934 & 40,934 & 40,934 & 40,934 \\
\hline & 5 & 27,462 & 27,462 & 27,462 & 27,462 & 27,462 \\
\hline & 6 & 27,524 & 27,524 & 27,524 & 27,524 & 27,524 \\
\hline \multirow{3}{*}{$\begin{array}{l}\text { Clonal } \\
\text { replicated } \\
\text { trials }\end{array}$} & 5 & 63,680 & 63,680 & 63,680 & 63,680 & 63,680 \\
\hline & 6 & 55,200 & 55,200 & 55,200 & 55,200 & 55,200 \\
\hline & 7 & 55,200 & 55,200 & 55,200 & 55,200 & 55,200 \\
\hline
\end{tabular}

${ }^{\mathrm{z}}$ Assumed that MAS is selecting for a simply inherited trait that decreases in effectiveness with subsequent generations. Selections cycle back as parents every 6 years and thus result in a reduction in MAS removal rates every 6 years.

Table 3. Marker-assisted selection (MAS) simulation 2 showing strawberry breeding program costs over 10 years of crosses with removal occurring after MAS application at the end of the greenhouse growth stage. ${ }^{\mathrm{z}}$ Examining discounts in MAS technology costs at three levels: $10 \%, 25 \%$, and $50 \%$.

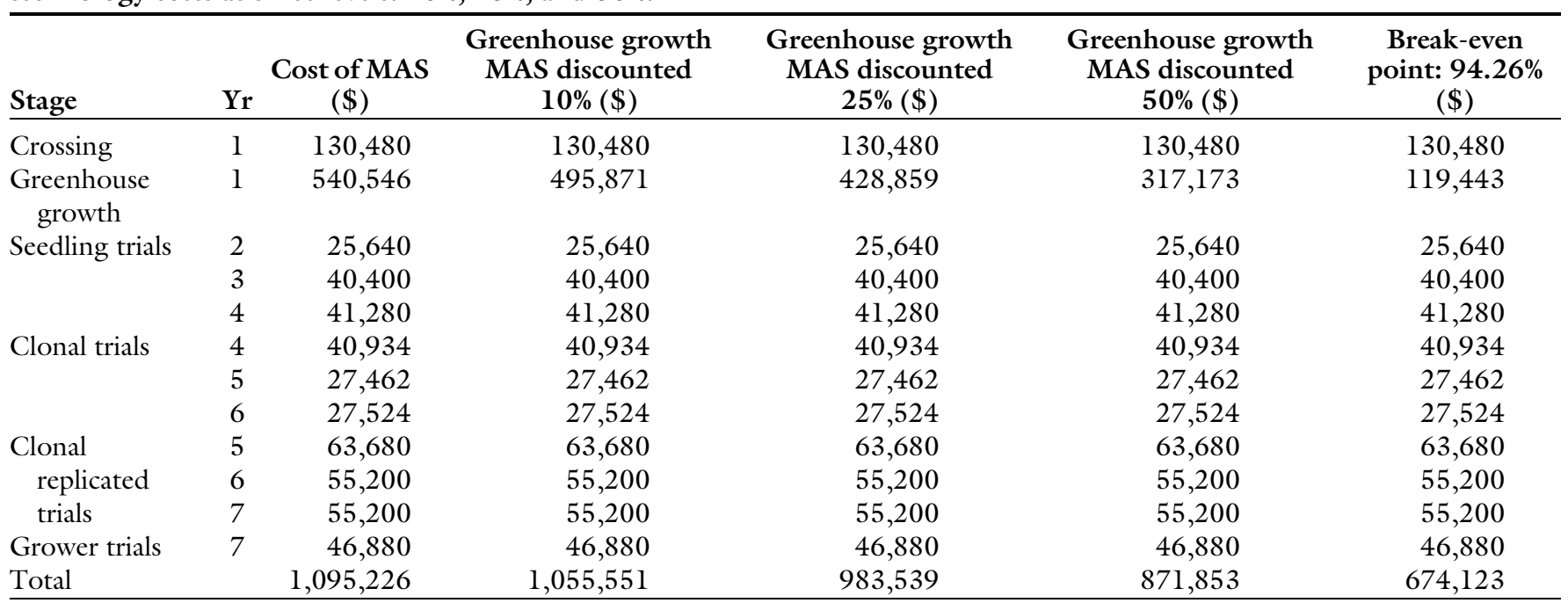

${ }^{\mathrm{z}}$ Assumed that MAS has constant effectiveness for removal of individual plants and that $50 \%$ removal is achieved of tested plants.

analysis was conducted examining evaluation costs, which constitute most of the remaining trial costs. The second sensitivity analysis examined evaluation labor cost discounts at $1 \%, 2 \%$, and $5 \%$ for each field trial stage, assuming everything else remains the same (Table 6).

\section{Results}

Conventional breeding. A traditional breeding program relies on examination of physical characteristics for breeding decisions and uses no MAS in the program. The number of seedlings entering field trials is greater than modeled programs using MAS. This increases total labor and consumable costs for seedling trials. Over a 10-year period, costs for crossing and greenhouse growth are about $\$ 130,480$ and $\$ 93,800$, respectively (Table 1). These stages account for $\approx 33 \%$ of total costs. As seedlings move to seedling trials, planting and maintenance for 3 years cost about \$3.79 per seedling with labor accounting for $94 \%$ of these costs. Then selections move to clonal trials with costs per replicated selection of
$\$ 57.50$ for propagation and maintenance. Selections are then planted and evaluated for 3 years at a cost of about \$122.00 per selection. Labor costs in clonal trials account for $\approx 83 \%$ of total clonal trial costs. The total cost for 10 years of crossing and subsequent evaluations of seedlings through grower trials amounts to $\$ 674,120$.

Application of MAS. Models were built to examine possible MAS application at the greenhouse growth stage before seedling trials. All procedural costs per individual were held 
constant across simulations for crossing stage, replicated clonal trials, and grower trials. Costs for conventional breeding are used for procedural costs. Additional costs were input for MAS including costs for DNA isolation, DNA normalization, and remontancy (perpetually flowering) testing, which totaled $\$ 446,746$ across 10 years in the breeding program. In conventional breeding, all the seedlings that germinate and appear vigorous would be planted into seedlings trials. The MAS model removed these seedlings by $50 \%$ for the first 6 years until selections were used as parents after which MAS removed $25 \%$ of seedlings. The additional costs and decrease in individuals resulted in a total cost of $\$ 1,100,354$ (Table 2). MAS increased costs over 10 years of crosses by $\$ 426,746$. To examine impacts of MAS costs on the program, MAS costs were discounted by $10 \%, 25 \%$, and $50 \%$. The discounts resulted in total costs of $\$ 1,055,679$,

Table 4. Marker-assisted selection (MAS) simulation 3 showing strawberry breeding program costs over 10 years of crosses with removal occurring after MAS application at the end of seedling trials before selection entry into clonal replication trials. ${ }^{\mathrm{z}}$ Three removal rates $(12.5 \%, 25 \%$, and $50 \%)$ were chosen based on predicted marker test results. No break-even point is presented as all scenarios are more cost-effective than conventional breeding and the addition of a single individual in the $\mathbf{1 2 . 5 \%}$ scenario exceeds the conventional cost of breeding.

\begin{tabular}{|c|c|c|c|c|c|}
\hline \multirow[b]{2}{*}{ Stage } & \multirow[b]{2}{*}{ Yr } & \multirow{2}{*}{$\begin{array}{l}\text { Conventional } \\
\text { breeding }(\$)\end{array}$} & \multicolumn{3}{|c|}{$\begin{array}{l}\text { MAS application with } \\
\text { removal rates of: }\end{array}$} \\
\hline & & & $12.5 \%$ & $25 \%$ & $50 \%$ \\
\hline Crossing & 1 & 130,480 & 130,480 & 130,480 & 130,480 \\
\hline Greenhouse growth & 1 & 93,800 & 93,800 & 93,800 & 93,800 \\
\hline \multirow[t]{3}{*}{ Seedling trials } & 2 & 51,280 & 51,280 & 51,280 & 51,280 \\
\hline & 3 & 40,400 & 40,400 & 40,400 & 40,400 \\
\hline & 4 & 41,280 & 51,917 & 51,917 & 51,917 \\
\hline \multirow[t]{3}{*}{ Clonal trials } & 4 & 40,934 & 35,792 & 30,855 & 20,570 \\
\hline & 5 & 27,462 & 24,702 & 20,700 & 13,977 \\
\hline & 6 & 27,524 & 24,739 & 20,436 & 13,762 \\
\hline \multirow{3}{*}{$\begin{array}{l}\text { Clonal replicated } \\
\text { trials }\end{array}$} & 5 & 63,680 & 63,680 & 63,680 & 63,680 \\
\hline & 6 & 55,200 & 55,200 & 55,200 & 55,200 \\
\hline & 7 & 55,200 & 55,200 & 55,200 & 55,200 \\
\hline Grower trials & 7 & 46,880 & 46,880 & 46,880 & 46,880 \\
\hline Total & & 674,120 & 674,070 & 660,828 & 637,146 \\
\hline
\end{tabular}

$\$ 988,667$, and $\$ 876,981$, respectively. The break-even point, where MAS becomes cost-effective and additional costs incurred by using markers equal cost savings, requires a $95.4 \%$ reduction in total MAS costs, which resulted in a program total of $\$ 674,115$ (Table 2).

A simulation was developed, holding removal rate constant at $50 \%$ under the assumption that breeders limit seedlings based on multiple parameters or characteristics (Table 3). Greenhouse growth and seedlings trials were adjusted to reflect a strict $50 \%$ removal rate each year in addition to $10 \%, 25 \%$, and $50 \%$ discounts for MAS costs. MAS incorporation under these assumptions resulted in a total cost of $\$ 1,095,226$, while discounts resulted in total costs of $\$ 1,050,551 \quad(10 \%), \quad \$ 983,539$ (25\%), and $\$ 871,853$ (50\%) (Table $3)$. These costs are higher compared with conventional breeding methods, so a break-even point analysis was conducted. For MAS to achieve cost-efficiency under these conditions, a cost discount of $94.26 \%$ from current costs must be achieved.

The final MAS simulation held procedures constant from crossing to the end of seedling trials and incorporated MAS at the end of seedling trials before selection entry into clonal trials (Table 4 ). The three removal rates were $12.5 \%, 25 \%$, and $50 \%$ reduction in the number of individuals entering clonal trials. Simulated incorporation of MAS before

Table 5. Sensitivity analysis (1) exploring potential cost discounts for seedling maintenance in a strawberry breeding program at three levels: $5 \%, 10 \%$, and $15 \% .^{\mathrm{z}}$ Breeding programs costs are over 10 years of crosses and subsequent evaluations.

\begin{tabular}{|c|c|c|c|c|c|}
\hline Stage & $\mathbf{Y r}$ & $\begin{array}{l}\text { Regular cost of } \\
\text { maintenance }(\$)\end{array}$ & $\begin{array}{c}\text { Maintenance discount } \\
\mathbf{5 \%}(\$)\end{array}$ & $\begin{array}{c}\text { Maintenance discount } \\
10 \%(\$)\end{array}$ & $\begin{array}{c}\text { Maintenance discount } \\
15 \%(\$)\end{array}$ \\
\hline Crossing & 1 & 130,480 & 130,480 & 130,480 & 130,480 \\
\hline $\begin{array}{l}\text { Greenhouse } \\
\text { growth }\end{array}$ & 1 & 540,546 & 540,546 & 540,546 & 540,546 \\
\hline \multirow{2}{*}{ Seedling trials } & 2 & 30,768 & 29,820 & 28,872 & 27,924 \\
\hline & 3 & 40,400 & 38,820 & 37,240 & 35,660 \\
\hline \multirow{2}{*}{ Clonal trials } & 5 & 27,463 & 26,969 & 26,476 & 26,115 \\
\hline & 6 & 27,524 & 27,034 & 26,411 & 25,923 \\
\hline \multirow{3}{*}{$\begin{array}{l}\text { Clonal replicated } \\
\text { trials }\end{array}$} & 5 & 63,680 & 62,690 & 61,700 & 60,710 \\
\hline & 6 & 55,200 & 54,210 & 53,220 & 52,230 \\
\hline & 7 & 55,200 & 54,210 & 53,220 & 52,230 \\
\hline Grower trials & 7 & 46,880 & 45,890 & 44,900 & 43,910 \\
\hline
\end{tabular}

${ }^{\mathrm{z}}$ Assumed that marker-assisted selection is selecting for a simply inherited trait that decreases in effectiveness with subsequent generations. Selections cycle back as parents every 6 years. 
Table 6. Sensitivity analysis (2) examining cost discounts over 10 years of crosses for seedling evaluations in a strawberry program at three levels: $1 \%, 2 \%$, and $5 \% .{ }^{\mathrm{z}}$ Breeding programs costs are over 10 years of crosses and subsequent evaluations.

\begin{tabular}{|c|c|c|c|c|c|}
\hline Stage & Yr & $\begin{array}{l}\text { Regular cost of } \\
\text { evaluation }(\$)\end{array}$ & $\begin{array}{c}\text { Evaluation discount } \\
1 \%(\$)\end{array}$ & $\begin{array}{c}\text { Evaluation discount } \\
2 \%(\$)\end{array}$ & $\begin{array}{c}\text { Evaluation discount } \\
\mathbf{5 \%}(\$) \\
\end{array}$ \\
\hline Crossing & 1 & 130,480 & 130,480 & 130,480 & 130,480 \\
\hline Greenhouse growth & 1 & 540,546 & 540,546 & 540,546 & 540,546 \\
\hline & 3 & 40,400 & 40,312 & 40,224 & 39,960 \\
\hline & 4 & 41,280 & 41,192 & 41,104 & 40,840 \\
\hline Clonal trials & 6 & 27,524 & 27,212 & 27,174 & 26,648 \\
\hline \multirow[t]{3}{*}{ Clonal replicated trials } & 5 & 63,680 & 63,326 & 62,972 & 61,910 \\
\hline & 6 & 55,200 & 54,846 & 54,492 & 53,430 \\
\hline & 7 & 55,200 & 54,846 & 54,492 & 53,430 \\
\hline Grower trials & 7 & 46,880 & 46,880 & 46,880 & 46,880 \\
\hline Total & & $1,100,355$ & $1,098,641$ & $1,096,717$ & $1,091,263$ \\
\hline
\end{tabular}

${ }^{\mathrm{z}}$ Assumed that marker-assisted selection is selecting for a simply inherited trait that decreases in effectiveness with subsequent generations. Selections cycle back as parents every 6 years.

clonal trials entry resulted in total costs of $\$ 674,070, \$ 660,828$, and $\$ 637,146$, respectively (Table 4). Compared with conventional breeding methods, these result in $0.007 \%$, $1.97 \%$, and $5.48 \%$ reduction in total costs.

Sensitivity ANALYsis: MaINTENANCE LABOR COST DISCOUNTS. This sensitivity analysis examined the relationship between three levels of discounts for maintenance labor costs (Table 5). The baseline model used MAS application before seedling trials and assumed a decreasing applicability of marker tests over time, with a total cost of $\$ 1,100,355$ over 10 crossing years. The three levels of discounted maintenance labor costs were $5 \%$, $10 \%$, and $15 \%$. The model used itemized costs for 10 crossing events with MAS application at the greenhouse growth stage, with decreasing MAS removal rates as selections become parents. The discounts resulted in total costs of $\$ 1,090,811 \quad(5 \%)$, $\$ 1,081,335(10 \%)$, and \$1,071,923 $(15 \%)$. Compared with the baseline model, these are $0.87 \%, 1.73 \%$, and $2.58 \%$ reductions in overall total costs.

SENSITIVITY anAlysis: Evaluation LABOR COST DISCOUNTS. This sensitivity analysis explored the impacts of more efficient evaluation labor by decreasing the evaluation labor costs (Table $6)$. The model of MAS application before field trials with decreasing marker applicability in the program was used as the baseline model with a total of $\$ 1,100,355$ over 10 crossing years. Evaluation labor costs were reduced by $1 \%, 2 \%$, and $5 \%$ based on theoretical improvements to program procedures resulting in total costs of $\$ 1,098,641 \quad(1 \%), \$ 1,096,717$ $(2 \%)$, and $\$ 1,091,263(5 \%)$. When compared with the base model, these result in cost savings of $0.16 \%, 0.33 \%$, and $0.83 \%$, respectively.

\section{Discussion and conclusions}

New technologies that have the potential to improve plant breeding efficiency are constantly coming into the market. One method is the use of DNA testing. DNA testing is shown to increase the likelihood of genetic gains while keeping costs relatively low in agronomic crops like maize and soybean. This makes the incentive to use DNA technology greater for perennial crops that have longer juvenile phases and costly maintenance programs. Previous studies indicate that efficient MAS incorporation can be achieved with early MAS applications in programs with extensive juvenile testing (EdgeGarza et al., 2015; Luby and Shaw, 2001). Edge-Garza et al. (2015) showed that MAS can be cost-effective at the early growth stage for both apple and grape programs. However, they found that in strawberry there was less internal cost-benefit to using MAS due to the low labor inputs per individual required for the programwhich is further confirmed in this study. MAS is not cost-effective because the cost of maintenance and evaluation is less than the cost of
MAS application early in the breeding program.

In the conventional breeding model, the costs for maintenance and evaluation over multiple years is minimal, and this factor makes MAS application at current prices inefficient (Table 2). This study shows that with a $50 \%$ reduction in MAS costs, the additional costs remain greater than conventional breeding methods. For cost-effective MAS before seedling trials, the current costs must decrease by $\approx 95.4 \%$. Although there has been a drastic reduction in MAS costs in the previous 5 years, the cost remains high because of the needed labor inputs of this technology (Luby and Shaw, 2001; Ru et al., 2015). However, application of MAS could become cost-effective if applied later in seedling trials before selections entering clonal trials. If markers exist that reduce the number of selections entering clonal trials, then cost-effective MAS could readily be achieved for this strawberry breeding program. This study assumed that a marker previously existed and could be readily implemented into the program. However, the development of a DNA test targeted for specific traits is challenging and comes with a substantial cost (for years) of measuring plant traits, sampling DNA, analyzing the data, and finally identifying a target area in the plant DNA. We recognize that the cost, both in terms of money and time, for developing markers is 
substantial and may inhibit organizations outside of research institutes.

In addition to examining MAS, this study further explores the capabilities of the tool developed by Wannemuehler et al. (2019) for use in estimation of costs and benefits associated with procedural variations beyond MAS. Because this tool requires inputs for the entire program and not just procedures associated with MAS, it can be used to examine changes at any point in the program. Assuming new technologies become available that decrease the need for extra evaluations or reduces the number of labor input needed for maintenance, this tool can capture these nuances. The maximum savings estimated for evaluation reduction was $0.67 \%$ $(-\$ 6,627)$, which is insignificant when compared with total program costs. However, this shows the tool's capabilities to handle variations breeders may wish to evaluate before implementing a new technology. Detailed inputs allow the tool flexibility to model a range of programs that previous decision support tools lacked. This means that though the results are limited to the program modeled here, the tool can be used in other programs and will allow breeders greater insight into their future budgeting when exploring new management or evaluation practices.

\section{Literature cited}

Alpuerto, V.L.E.B., G.W. Norton, J. Alwang, and A.M. Ismail. 2009. Economic impact analysis of marker-assisted breeding for tolerance to salinity and phosphorous deficiency in rice. Rev. Agr. Econ. 31:779-792.

Chandler, C.K., K. Folta, A. Dale, V.M. Whitaker, and M. Herrington. 2012. Strawberry, p. 305-325. In: M. Badenes and D. Byrne (eds.). Fruit breeding. Springer, Boston, MA.

Collard, B.C. and D.J. Mackill. 2008. Marker-assisted selection: An approach for precision plant breeding in the twenty- first century. Phil. Trans. Royal Soc. B Bio. Sci. 363:557-572.

Dreher, K., M. Khairallah, J.M. Ribaut, and M. Morris. 2003. Money matters (I): Costs of field and laboratory procedures associated with conventional and markerassisted maize breeding at CIMMYT. Mol. Breed. 11:221-234.

Edge-Garza, D.A., J.J. Luby, and C. Peace. 2015. Decision support for cost-efficient and logistically feasible marker-assisted seedling selection in fruit breeding. Mol. Breed. 35:1-15.

Faedi, W., F. Mourgues, and C. Rosati. 2002. Strawberry breeding and varieties: Situation and perspectives. Acta Hort. 567:51-59.

Frey, J.E., B. Frey, C. Sauer, and M. Kellerhals. 2004. Efficient low-cost DNA extraction and multiplex fluorescent PCR method for marker-assisted selection in breeding. Plant Breed. 1231:554-557.

Hancock, J.F., H.S. Donald, and F.J. Lawrence. 1996. Strawberries, p. 419470. In: J. Janick and J.N. Moore (eds.) Fruit breeding. Vol. 2: Vine and small fruits. Wiley, New York, NY.

Hancock, J.F., T.M. Sjulin, and G.A Lobos. 2008. Strawberries, p. 393-437. In: J.F. Hancock (ed.). Temperate fruit crop breeding. Springer, Dordrecht, The Netherlands.

Hoeck, J.A., W.R. Fehr, R.C. Shoemaker, G.A. Welke, S.L. Johnson, and S.R. Cianzio. 2003. Molecular marker analysis of seed size in soybean. Crop Sci. 43:6874.

Johnson, R. 2003. Marker-assisted selection. Plant Breed. Rev. 24:293-309.

Knapp, S.J. 1998. Marker-assisted selection as a strategy for increasing the probability of selecting superior genotypes. Crop Sci. 38:1164-1174.

Kuchel, H., G. Ye, R. Fox, and S. Jefferies. 2005. Genetic and economic analysis of a targeted marker-assisted wheat breeding strategy. Mol. Breed. 16:67-78.

Luby, J.J. and D.V. Shaw. 2001. Does marker-assisted selection make dollars and sense in a fruit breeding program? HortScience 36:872-879.
Miles, C. and M. Wayne. 2008. Quantitative trait locus (QTL) analysis. Nature Educ. 1:208.

Morris, M., K. Dreher, J.M. Ribaut, and M. Khairallah. 2003. Money matters (II): Costs of maize inbred line conversion schemes at CIMMYT using conventional and marker-assisted selection. Mol. Breed. 11:235-247.

Ru, S., D. Main, K. Evans, and C. Peace. 2015. Current applications, challenges, and perspectives of marker-assisted seedling selection in Rosaceae tree fruit breeding. Tree Genet. Genomes 11:8.

Shulaev, V., D.J. Sargent, R.N. Crowhurst, T.C. Mockler, O. Folkerts, A.L. Delcher, P. Jaiswal, K. Mockaitis, A. Liston, S.P. Mane, and P. Burns. 2011. The genome of woodland strawberry (Fragaria vesca). Nat. Genet. 43:109-118.

Slater, A.T., N.O. Cogan, and J.W. Forster. 2013. Cost analysis of the application of marker-assisted selection in potato breeding. Mol. Breed. 32:299-310.

Stromberg, L.D., J.W. Dudley, and G.K. Rufener. 1994. Comparing conventional early generation selection with molecular marker assisted selection in maize. Crop Sci. 34:1221-1225.

Wannemuehler, S.D., J.J. Luby, C. Yue, D.S. Bedford, R.K. Gallardo, and V.A. McCracken. 2019. A cost-benefit analysis of DNA informed apple breeding. HortScience 54:1998-2004.

Whitaker, V.M. 2011. Applications of molecular markers in strawberry. J. Berry Res. 1:115-127.

Yue, C., R.K. Gallardo, J. Luby, A. Rihn, J.R. McFerson, V. McCracken, V.M. Whitaker, C.E. Finn, J.F. Hancock, C. Weebadde, and A. Sebolt. 2014. An evaluation of US strawberry producers' trait prioritization: Evidence from audience surveys. HortScience 49:188-193.

Yue, C., R.K. Gallardo, V.A. McCracken, J. Luby, J.R. McFerson, L. Liu, and A. Iezzoni. 2012. Technical and socioeconomic challenges to setting and implementing priorities in North American rosaceous fruit breeding programs. HortScience 47:1320-1327. 